\title{
URS Sonrası Stent Yerleştirme: Gerçekten Gerekli Mi?
}

\author{
Ali Güneş ${ }^{1}$, İbrahim Topçu ${ }^{1}$, Mehmet Levent Akbulut ${ }^{1}$
}

${ }^{1}$ Inönü Üniversitesi, Turgut Özal Tıp Merkezi, Üroloji Anabilim Dalı, Malatya

Üm reteral taşların tedavisi teknolojinin ilerlemesine paralel olarak gelişmektedir (1). Ekstrakorporeal taş kırma (ESWL) ve üreteroskopi en sik başvurulan yöntemlerdir. Çoğu üroloji uzmanı üreteroskopi sonrası rutin olarak stent yerleştirmektedir. Stent yerleştirilmesindeki ana amaç taşın kırılması veya balon dilatasyonu sonrası meydana gelebilecek olan, üreteral ödeme bağlı postoperatif renal koliği azaltmak ve üreteral darlık riskini düşürmektir (2). Stent yerleştirilmesi ile rezidü taş kırıntılarının üreterin pasif dilatasyonu ile daha kolay düşürülmesi amaçlanmaktadır (3). Ek olarak stentle böbreğin fonksiyonunun korunduğu, postoperatif ağrının da azaldığı görülmektedir (4).

Ancak stent yerleştirilmesi ağrı, enfeksiyon ve alt üriner sistem semptomları nedeniyle hastaların hayat kalitesini düşürmektedir $(5,6)$. Ayrıca stentle ilişkili nadir komplikasyonlar olan stentin enkrustasyonu ve taşlaşması ve buna bağlı olarak üst ve alt üriner sistem enfeksiyonları görülebilmektedir (7). Bu nadir komplikasyonlar nedeni ile daha invazif tedaviler gerekebilir ve sonuçta da ağır komplikasyonlar meydana gelebilir $(8,9)$. Stentlerin enkrustasyonu kabaca 4. Haftada \%15, 3 ayda \%75 oranında meydana gelir (10). Stentin maliyeti ve çıkarılması için gerekli olan sistoskopi operasyonu da hasta bakım masraflarını arttırmaktadır.

Ureteroskopi son zamanlarda daha ince kalibrasyondaki aletler ile uygulanmakta ve daha iyi litotriptörler ile (Holmium lazer gibi) taş kırılmaktadır. Böylece iatrojenik travmalar daha az görülmekte ve üreteral dilatasyona daha az ihtiyaç duyulmaktadır. Bu nedenle günümüzde üreteroskopi sonrası rutin stent yerleştirilmesi daha fazla sorgulanır hale gelmiştir $(1,11)$. EAU klavuzunun son güncellemesine göre komplikasyonsuz bir üreteroskopi sonrası rutin stent yerleştirilmesi gerekmemektedir (öneri derecesi A ve kanıt derecesi 1a).

\section{Tartışılması Gereken Noktalar}

Postoperatif oluşabilecek komplikasyonları önlemek amacı ile üreteroskopik litotripsi ve balon dilatasyonu sonrası stent takılması genelde kabul gören bir işlemdir. Buradaki amaç üreteral geçişi açık tutmaktır $(2,3)$. Daha küçük kalibredeki üreteroskopların kullanılması ile üretere girmek ve üreter boyunca seyretmek daha kolay olmaktadır. Ayrıca balon dilatasyonuna nadiren ihtiyaç duyulmaktadır. Bunun yanında daha iyi litotriptörlerin kullanılması ile taşlar daha küçük parçalara ayrılmaktadır. Bu nedenle postoperatif rutin olarak stent yerleştirilmesi sorgulanmaktadır.

Joshi ve ark.'ları üreteral stente bağlı hasta morbiditesinin önemli bir problem olduğunu ve bunun ayrıntılı bir şekilde araştırılması gerektiğini söylemektedirler (12). Üreteral stentlerin hayat kalitesini düşürdüğünü ve günlük yaşamı etkileyebilecek düzeyde ağrı (\%80), üriner semptomlar (\%73), çalışma gücünün kaybına (\%58) yol açtıklarını saptamışlardır. Sonuç olarak stentlerin fiziksel ve psikolojik sağlığı etkilediği; fonksiyonel kapasite ve çalışma performansına negatif etkisi olduğu raporlanmıştır $(5,12)$. Diğer taraftan El Harrech ve ark'ları, üreteroskopi yapılan 117 hastayı aldıkları çalışmalarında hastaları 3 gruba ayırarak değerlendirmişlerdir. Bir gruba stent takılmış, bir gruba ertesi gün çıkarılmak üzere üreteral kateter takılmış, son gruba üreteroskopi sonrası herhangi bir müdahelede bulunulmamıştır. Çalışma sonucunda yan ağrısı, hematüri, ateş ve idrar yolu enfeksiyonu açısından anlamlı fark bulunmazken stent yerleştirilen hastalarda, yerleştirilmeyen hastalara göre daha sık disüri, urgency ve pollaküri izlenmiştir. Yine analjezik ihtiyacı stent yerleştirilen hastalarda diğer gruplara göre anlamlı olarak daha fazla bulunmuştur (13). Diğer taraftan İbrahim ve ark.'ları stent takılan ve takılmayan gruplar arasında subfebril ateş, hematüri ve idrar yolu enfeksiyonu gibi erken postoperatif komplikasyonların varlığı, ortalama hospitalizasyon süresi, fiziksel aktiviteye geri dönüş süresi ve yan ağrısını araştırmışlar ve gruplar arasında anlamlı farklılık bulmamışlardır (14). Borboroğlu ve ark.'ları da; çok merkezli randomize kontrollü prospektif bir çalışmada stent takılmayan grupta takılanlara göre anlamlı olarak daha az yan ağrısı olduğunu raporlamışlardır (15).

$\mathrm{Bu}$ konuda yapılan metaanalizler belki de en güvenilir bilgiyi sağlamaktadır. Nabi ve ark.'ları 9 randomize kontrollü çalışmanın meta-analizinde, komplike olmayan üreteroskopi sonrası stent takılan hastalarda anlamlı olarak üriner sistem semptomlarının daha yüksek olduğunu göstermişlerdir (16). Song ve ark.'ları 1496 hastanın dahil edildiği bir meta-analizde 11 çalışmada stentli grupta \%100 taşsızlık sağlandığını (12,13,15,18-22), 1 çalışmada ise; stentsiz grupta \%100 taşsızlık sağlandığını bildirmişlerdir (17). Diğer taraftan stentsiz gruplarda ise \%97 oranında taşsızlık sağlandığ ve aradaki küçük farkın, fragmanların yetersiz düşürülmesine bağlı olduğunu bidirmişlerdir $(p>0.05)(14,23)$. Rapor edilen darlık oranları stentli çalışmalarda \%0.9-6.9, stentsiz gruplarda ise \%1.8-17.2 aralığındadır. Taburculuk sonrası 14 tanesi stent yerleştirilen gruptan olmak üzere 44 hasta tekrar hastaneye başvurmuştur. Bu hastalardan stent yerleştirilmeyenlerden 2 tanesine stent takılmış, stent takılan gruptan da 


\section{URS SONRASI STENT YERLEŞTIRME: GERÇEKTEN GEREKLI Mi?}

bir tanesinin stenti düştüğü için çekilmiştir. Genel olarak bu alanda da anlamlı farklılık saptanmamıştır (17).

Stent yerleştirilmesi durumunda bir süre sonra stenti çıkarmak için sistoskopi yapılması gerekmektedir. Richer ve ark.'ları bu durumu "arkadaşça prosedür sonrası düşmanca yüksek morbidite" olarak tanımlamaktadır. Sistoskopi gerekliliği rahatsız edici ve fazladan maliyetli bir durumdur (8).

Daha uzun operasyon süresi, stentin maliyeti ve stentin çıkarılması için gereken sistoskopik müdahele nedeni ile hasta maliyeti daha da artmaktadır. Türkiye'deki maliyeti 950 dolar olarak hesaplanmıştır (18). Sonuçta, üreteroskopi sonrası rutin stent yerleştirilmesi potansiyel komplikasyonları, hasta hayat kalitesinine olan negatif etkisi ve fazladan maliyeti nedeni ile rutin olarak yapılmamalı, üreteral yaralanma veya tıkayıcı olabilecek büyük taşların varlığında düşünülmelidir.

\section{Sonuç}

Komplike olmayan ureteroskopi sonrası özellikle alt üreter taşları veya balon dilatasyonu yapılmayan durumlarda güvenle stent yerleştirilmeden işlem sonlandırılabilir. Yapılan çalışmalarda stent yerleştirilen hastalarda, yerleştirilmeyen hastalara göre postoperatif komplikasyonlarda ve hasta morbiditesinde anlamlı olarak artış olduğu görülmektedir. Güncel EAU klavuzuna göre de sorunsuz bir üreteroskopiden sonra rutin olarak stent yerleştirilmesi gerekmemektedir.

\section{Kaynaklar}

1. Gettman MT, Segura JW. Management of ureteric stones: issues and controversies. BJU Int 2005;95(suppl 2):85-93.

2. Knudsen BE, Beiko DT, Denstedt JD (2004) Stenting after ureteroscopy: pros and cons. Urol. Clin North Am 31:173180.

3. Harmon WJ, Sershon PD, Blute ML et al (1997) Ureteroscopy: current practice and long term complications. J Urol 157:28.

4. D. H. Hosking, S. E. McColm, and W. E. Smith, "Is stenting following ureteroscopy for removal of distal ureteral calculi necessary?" Journal of Urology, vol. 161, no. 1, pp. 48-50, 1999.

5. H. B. Joshi, N. Newns, A. Stainthorpe, R. P. MacDonagh, F. X. Keeley Jr., and A. G. Timoney, "Ureteral stent symptom questionnaire: development and validation of a multidimensional quality of life measure," Journal of Urology, vol. 169, no. 3, pp. 1060-1064, 2003.

6. M. Duvdevani, B. H. Chew, and J. D. Denstedt, "Minimizing symptoms in patients with ureteric stents," Current Opinion in Urology, vol. 16, no. 2, pp. 77-82, 2006.

7. Singh I, Gupta NP, Hemal AK, Aron M, Seth A, Dogra PN. Severely encrusted polyurethane ureteral stents: management and analysis of potential risk factors. Urology 2001;58:526-31.
8. S. Richter, A. Ringel, M. Shalev, and I. Nissenkorn, "The indwelling ureteric stent: a "friendly" procedure with unfriendly high morbidity," BJU International, vol. 85, no. 4, pp. 408-411, 2000.

9. Baldwin DD, Juriansz GJ, Stewart S et al (1998) Knotted ureteral stent: a minimally invasive technique for removal. J Urol 159:2065-2066.

10. Byrne RR, Auge BK, Kourambas J et al (2002) Routine ureteral stenting is not necessary after ureteroscopy and ureteropyeloscopy; a randomized trial. J. Endourol 16:913.

11. Ryan PC, Lennon GM, McLean PA, Fitzpatrick JM. The effects of acute and chronic JJ stent placement on upper urinary tract motility and calculus transit. Br J Urol 1994;74:434-9.

12. H. B. Joshi, A. Stainthorpe, R. P. MacDonagh, F. X. Keeley Jr., and A. G. Timoney, "Indwelling ureteral stents: evaluation of symptoms, quality of life and utility," Journal of Urology, vol. 169, no. 3, pp. 1065-1069, 2003.

13. El Harrech Y, Abakka N, El Anzaoui J, Ghoundale $\mathrm{O}$, Touiti D, “Ureteral stenting after uncomplicated ureteroscopy for distal ureteral Stones: A randomized, controlled trial," Minimally i-Invasive Surgery, vol.2014, art ID 892890.

14. H. M. Ibrahim, A. M. Al-Kandari, H. S. Shaaban, Y. H. Elshebini, and A. A. Shokeir, "Role of ureteral stenting after uncomplicated ureteroscopy for distal ureteral stones: a randomized, controlled trial," Journal of Urology, vol. 180, no. 3, pp. 961-965, 2008.

15. P.G. Borboroglu, C.L. Amling, N. S. Schenkmanet al., “Ureteral stenting after ureteroscopy for distal ureteral calculi: a multiinstitutional prospective randomized controlled study assessing pain, outcomes and complications," Journal of Urology, vol. 166, no. 5, pp. 1651-1657, 2001.

16. G. Nabi, J. Cook, J. N’Dow, and S. McClinton, “Outcomes of stenting after uncomplicated ureteroscopy: systematic review and meta-analysis," British Medical Journal, vol. 334, no. 7593, pp. 572-575, 2007.

17. Song T, Banghua L, Shuo Z, Wei Q, "Meta-analysis of postoperatively stentin or not in patients underwent ureteroscopic lithotripsy,"Urol Res, vol. 40:67-77, 2011.

18. Kenan I, Salih B, Suat E et al (2008) Is routine ureteral stenting necessary after uncomplicated ureteroscopic lithotripsy for lower ureteral Stones larger than $1 \mathrm{~cm}$ ? Urol Res 36(2):115-119.

\section{Yazışma Adresi:}

İbrahim Topçu,

İnönü Üniversitesi, Turgut Özal Tıp Merkezi, Üroloji Anabilim Dall, Battalgazi, 44220, Malatya

Tel: +904223410660 / 5823

e-mail: ibrahimtopcu15@hotmail.com 